\title{
Lung cancer risk at low radon exposure rates in German uranium miners
}

\author{
M Kreuzer ${ }^{\star}, 1$, N Fenske ${ }^{1}$, M Schnelzer ${ }^{1}$ and L Walsh ${ }^{1}$ \\ ${ }^{1}$ Department of Radiation Protection and Health, Federal Office for Radiation Protection, Neuherberg, Germany
}

Background: A determination of the risk of lung cancer at low levels of radon exposure is important for occupational radiation protection.

Methods: The risk of death from lung cancer at low radon exposure rates was investigated in the subcohort of 26766 German uranium miners hired in 1960 or later.

Results: A clear association between lung cancer mortality $(n=334$ deaths) and cumulative exposure to radon in working level months (WLM) was found. The excess relative risk per WLM was 0.013 (95\% confidence intervals: 0.007; 0.021).

Conclusions: The present findings provide strong evidence for an increased lung cancer risk after long-term exposure to low radon exposure rates among Wismut miners. The results are compatible to those from residential radon studies and miner studies restricted to low levels.

There is strong scientific evidence from miner and residential radon studies that radon and its progeny cause lung cancer (UNSCEAR, 2009). Many of the cohorts on occupationally exposed miners include large numbers of individuals who worked in the 1940s and 1950s, when radon concentrations were extremely high. Such conditions do not reflect current occupational exposure scenarios of around two working level months (WLM) per year. Only a few miner studies provide risk estimates for long-term exposure to very low levels of radon (NRC, 1999; Tomasek et al, 2008a; Hunter et al, 2013; Zablotska et al, 2013; Kreuzer et al, 2014; Rage et al, 2014). Such risks, however, are highly relevant for current occupational radiation protection and calculation of lifetime risks for conversions from WLM into effective dose (Tomasek et al, 2008b). Extrapolation of risk from indoor radon studies to miners is difficult due to differences in duration of exposure, exposure to other occupational carcinogens and breathing rates.

The German miner cohort study offers a unique opportunity to investigate the lung cancer risk following occupational radon exposure at low exposure rates in miners. For this purpose, the subcohort of miners hired in 1960 or later $(1960+$ subcohort) was used, which is characterised by uniform very low exposure rates (average 0.2 working level) over a long time, high quality of exposure assessment and availability of individual data on important potential confounders.

\section{MATERIALS AND METHODS}

The German 'Wismut' uranium miner study has been described in detail elsewhere (Walsh et al, 2015). The full cohort includes 58982 men employed for at least 6 months between 1946 and 1989 in the uranium mining company Wismut in East Germany. The present analyses are based on the third mortality follow-up from 1 January 1960 to 31 December 2008 and include only workers hired in 1960 or later. Vital status was provided by local registration offices. Causes of deaths were obtained from death certificates and autopsy files from the Wismut pathology archive.

Data collection. Exposure to radon and its progeny, long-lived radionuclides from uranium ore dust and external gamma radiation were determined from a comprehensive job-exposure matrix (JEM). Cumulative exposures are given in WLM for radon progeny, in $\mathrm{mSv}$ for the effective dose from external gamma radiation and in $\mathrm{kBqh} \mathrm{m}^{-3}$ for long-lived radionuclides from uranium ore dust. Annual cumulative WLM from the JEM relate to ambient measurements of radon gas and estimated equilibrium factors from 1960 to 1964 and of radon progeny after 1964 .

Information on smoking habits was obtained from the Wismut Health Archives, mainly from the documented post-1969 regular medical check-ups. Three smoking categories were defined:

*Correspondence: Dr M Kreuzer; E-mail: mkreuzer@bfs.de

Received 10 April 2015; revised 22 July 2015; accepted 14 August 2015; published online 22 September 2015

(c) 2015 Cancer Research UK. All rights reserved 0007-0920/15 
'non-smoker' (in all years 'non-smoker'), 'moderate/heavy smoker' (if in any year the classification 'more than 5 years of smoking or more than 10 cigarettes smoked per day' was indicated) and 'light smoker' (for all other specifications such as 'occasional smoker', 'less than 5 years or less than 10 cigarettes smoked per day', 'cigar/pipe smoked'). Only the current smoking habits in a given year were documented in predefined categories, so for the 'non-smoker' category a distinction between lifelong non-smokers and ex-smokers is not possible.

Statistical methods. Internal Poisson regression was applied to model lung cancer mortality rates depending on radon, similar to previous publications (Walsh et al, 2010). A grouped data set was created with the following cross-classifications: age and calendar year in 5-year intervals, duration of employment (0-4, 5-14 and $15+$ years), cumulative 5-year lagged radon exposure $w(0,>0-9$, $10-49,50-99,100-199$ and $200+$ WLM), smoking in four categories and for 5-year lagged cumulative exposures to potential confounders. A linear model was fitted, $\operatorname{ERR}(w)=\beta w$, where $\beta$ quantifies the excess relative risk (ERR) per unit of cumulative radon exposure; 95\% profile likelihood-based confidence intervals (CIs) were derived. In order to evaluate potential confounders, risk estimates were separately adjusted for external gamma radiation, long-lived radionuclides, silica dust and smoking. Effect modification by time since or age at exposure and exposure rate was tested as in previous publications (Walsh et al, 2010).

\section{RESULTS}

The $1960+$ subcohort is relatively young; at end of follow-up $83.5 \%$ are alive (Table 1). The mean duration of employment was 10 years (range: $0.5-30$ years), and the mean age at first employment was 21 years (range: 13-68 years). Information on smoking status was available for $56 \%$ of the subcohort members. Among those with known smoking status, 23\% were non-smokers, $19 \%$ light smokers and 58\% were moderate/heavy smokers. The corresponding numbers for individuals with lung cancer and known smoking status $(n=172)$ are $5 \%, 8 \%$ and $87 \%$, respectively.

A statistically significant linear association between lung cancer mortality and cumulative radon exposure (ERR/WLM $=0.013$; 95\% CI: 0.007 ; 0.021) was found (Figure 1; Supplementary Table 1). Other models (such as linear quadratic or log linear) did not improve significantly the model fit (Supplementary Table 2). Separate adjustment for smoking status, external gamma radiation, long-lived radionuclides or silica dust led only to minor changes in the radon-related risk coefficient. A cutoff of radon exposures to $<100$ or 50 WLM resulted in a significant ERR/WLM of 0.016 or 0.013 , respectively. There was no indication that the ERR/WLM differs by time since or age at median exposure or exposure rate (Supplementary Table 2). The ERR/WLM for non-/ light smokers was slightly higher than that for moderate/heavy smokers, however, CIs broadly overlap. Exclusion of short-term employees ( $<5$ years) led to an increased risk estimate (ERR/ $\mathrm{WLM}=0.019 ; 95 \% \mathrm{CI}: 0.011 ; 0.032)$.

\section{DISCUSSION}

The present study shows a clear statistically significant association between lung cancer mortality and low cumulative radon exposure $(\mathrm{ERR} / \mathrm{WLM}=0.013 ;$ 95\% CI: $0.007 ; 0.021)$ in Wismut uranium miners. Strengths of the Wismut $1960+$ subcohort are the large number of long-term workers in this exposure range, a long followup period, a large number of lung cancer deaths and person-years at risk, leading to a high statistical power. Potential confounders such as external gamma radiation, long-lived radionuclides, silica
Table 1. Characteristics of the $1960+$ German Wismut cohort including workers hired in 1960 or later

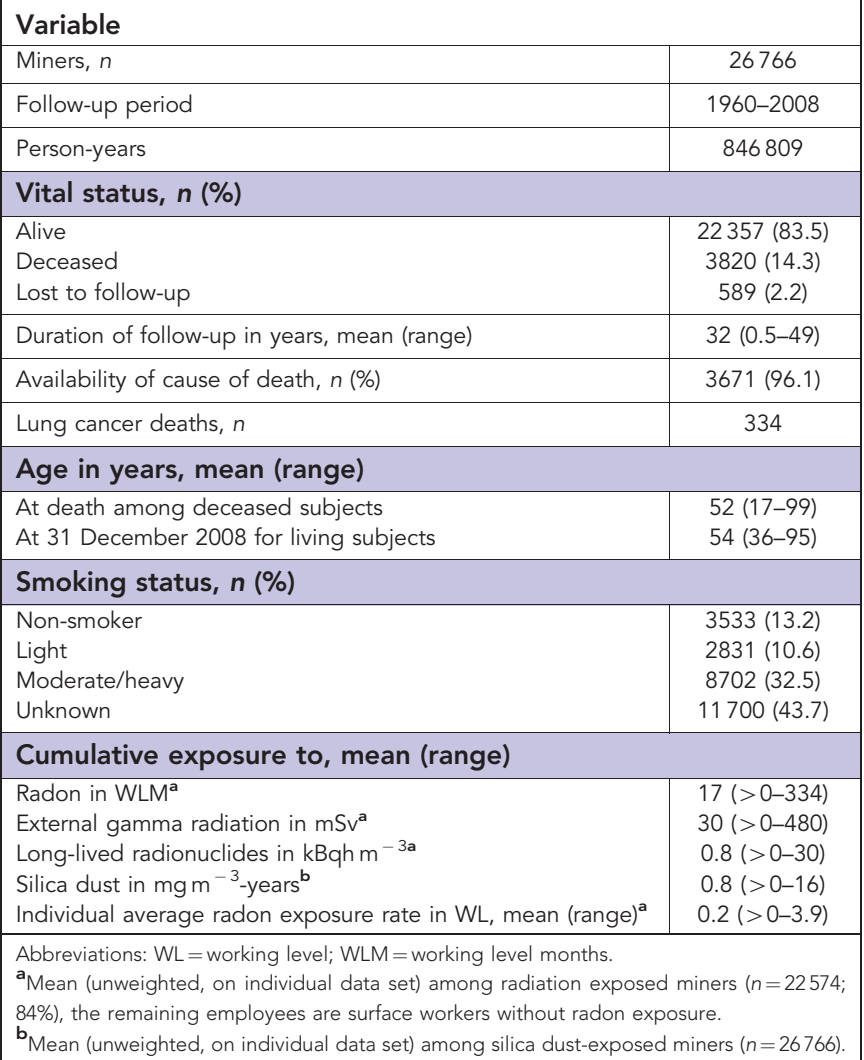

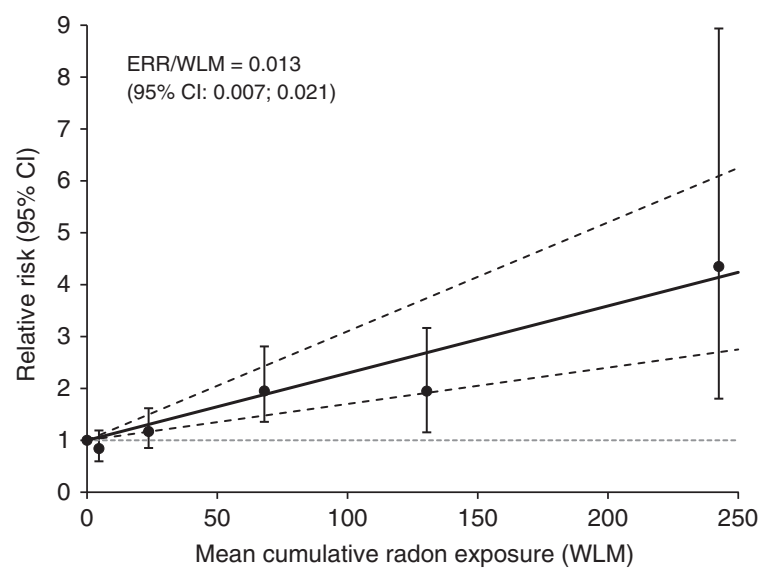

Figure 1. Relative risk for death from lung cancer in relation to cumulative radon exposure in the $1960+$ subcohort of miners hired in 1960 or later. Results for categorical analysis $(0,>0-10,10-50,50-100,100-200$, $200+$ WLM) and excess relative risk (ERR) per WLM based on linear model (bold line) with 95\% likelihood-based confidence intervals (Cl).

dust and smoking could be controlled for and it was found that major confounding of the radon-related risk by these factors is unlikely. Even though all radon values were based on ambient measurements (instead of expert rating), some potential bias from uncertainty in exposure assessment and residual confounding by smoking cannot be entirely ruled out.

Findings from other miner studies. Previously, several approaches were used to determine the lung cancer risk associated with low cumulative radon exposures or exposure rates in miner cohorts. One approach was to apply the BEIR VI categorical 


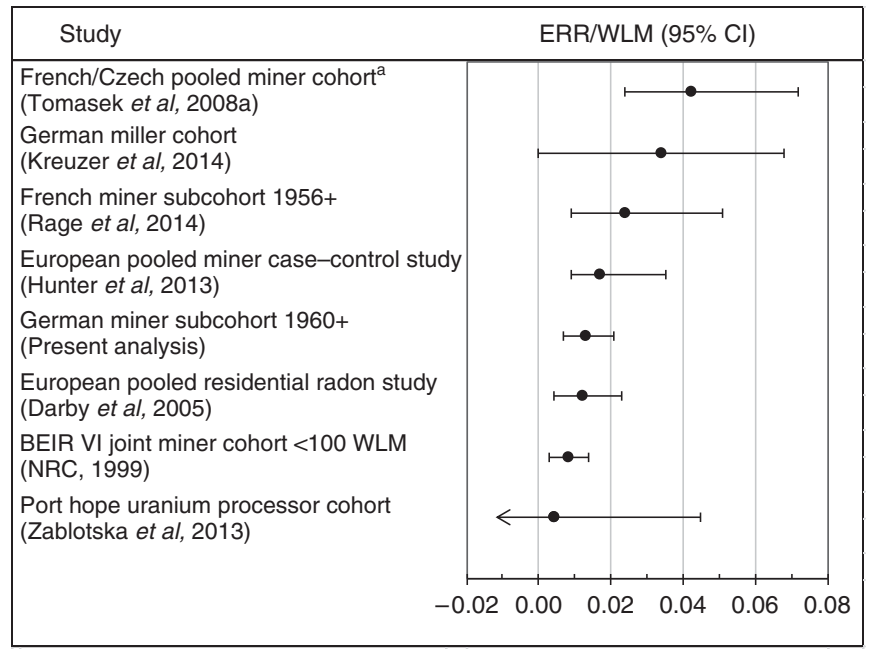

Figure 2. Overview on lung cancer mortality risk in relation to cumulative radon exposure from published miner studies with focus on low cumulative radon exposures or exposure rates and the European pooled residential radon study. Estimated excess relative risk (ERR) per WLM and 95\% confidence intervals. More information can be found in Supplementary Table 3. ${ }^{a} E R R / W L M$ at age at median exposure 30 years, time since median exposure 20 years and related only to measured exposure.

exposure-age-concentration model and to calculate the risk related to the exposure rate category $<0.5 \mathrm{WL}(\mathrm{NRC}, 1999)$. However, a formal test of statistical significance of the ERR/WLM in this category cannot be directly derived. Another approach that seems more appropriate is setting a cutoff at low exposures (e.g., 100 or $50 \mathrm{WLM}$ ) or including only a subgroup of workers with low exposure rates (e.g., those with a later begin of employment or millers; Supplementary Table 3). The majority of these studies show a statistically significant relationship between lung cancer risk and cumulative exposure to radon and no effect modification by time since or age at exposure. The observed risk coefficients are broadly consistent and range from 0.004 to 0.042 (see Figure 2).

Findings from residential radon studies. In a European pooled analysis of residential radon studies, an ERR per $100 \mathrm{~Bq} \mathrm{~m}^{-3}$ of 0.16 (95\% CI: 0.05 ; 0.31$)$ overall and of 0.25 (95\% CI: $0.09 ; 0.49)$ for men was found after correction for measurement error (Darby et al, 2005). By using the conversion factor from Hunter et al (2013), a residential cumulative radon exposure of $100 \mathrm{~Bq} \mathrm{~m}^{-3}$ over 30 years assuming $7000 \mathrm{~h}$ per year spent in homes corresponds to 13.2 WLM. Thus, for men and women, the overall ERR/WLM is $0.16 / 13.2=0.012$ (95\% CI: $0.004 ; 0.023$ ) and 0.019 (95\% CI: 0.007 ; 0.037) for men only. This risk coefficient is compatible to the risk observed in the present study.

\section{CONCLUSION}

The present study demonstrates a clearly increased excess risk of lung cancer at low radon exposure rates among German uranium miners. The risk coefficients are of high precision and well controlled for potential confounders. Results are broadly consistent to other miner studies at low exposures or exposure rates and to indoor radon studies.

\section{CONFLICT OF INTEREST}

The authors declare no conflict of interest.

\section{REFERENCES}

Darby S, Hill D, Auvinen A, Barros-Dios JM, Baysson H, Bochicchio F, Deo H, Falk R, Forastiere F, Hakama M, Heid I, Kreienbrock L, Kreuzer M, Lagarde F, Mäkeläinen I, Muirhead C, Oberaigner W, Pershagen G, Ruano-Ravina A, Ruosteenoja E, Rosario AS, Tirmarche M, Tomásek L, Whitley E, Wichmann HE, Doll R (2005) Radon in homes and risk of lung cancer: collaborative analysis of individual data from 13 European case-control studies. BMJ 330: 223.

Hunter N, Muirhead CR, Tomasek L, Kreuzer M, Laurier D, Leuraud K, Schnelzer M, Grosche B, Placek V, Heribanova A, Timarche M (2013) Joint analysis of three European nested case-control studies of lung cancer among radon exposed miners: exposure restricted to below 300 WLM. Health Phys 104: 282-292.

Kreuzer M, Dufey F, Laurier D, Nowak D, Marsh JW, Schnelzer M, Sogl M, Walsh L (2014) Mortality from internal and external radiation exposure in a cohort of male German uranium millers, 1946-2008. Int Arch Occup Environ Health 88: 431-441.

NRC (1999) Committee on Health Risks of Exposure to Radon. Board on Radiation Effects Research. Health effects of exposure to radon. BEIR VI report. National Academy Press: Washington, DC.

Rage E, Caer-Lorho S, Drubay D, Ancelet S, Laroche P, Laurier D (2014) Mortality analyses in the updated French cohort of uranium miners (1946-2007). Int Arch Occup Environ Health 88: 717-730.

Tomasek L, Rogel A, Tirmarche M, Mitton N, Laurier D (2008a) Lung cancer in French and Czech uranium miners: radon-associated risk at low exposures and modifying effects of time since exposure and age at exposure. Radiat Res 169: 125-137.

Tomasek L, Rogel A, Laurier D, Tirmarche M (2008b) Dose conversion of radon exposure according to new epidemiologic findings. Radiat Prot Dosimetry 130: 98-100.

UNSCEAR (2009) UNSCEAR 2006 Report. Annex E. Sources-to-Effects Assessment for Radon in Homes and Workplaces. United Nations: New York, NY.

Walsh L, Tschense A, Schnelzer M, Dufey F, Grosche B, Kreuzer M (2010) The influence of radon exposures on lung cancer mortality in German uranium miners, 1946-2003. Radiat Res 173: 79-90.

Walsh L, Grosche B, Schnelzer M, Tschense A, Sogl M, Kreuzer M (2015) A review of the results from the German Wismut uranium miners cohort. Radiat Prot Dosimetry 164: 147-153.

Zablotska LB, Lane RS, Frost SE (2013) Mortality (1950-1999) and cancer incidence (1969-1999) of workers in the Port Hope cohort study exposed to a unique combination of radium, uranium and $\gamma$-ray doses. BMJ Open 27: 3 .

This work is published under the standard license to publish agreement. After 12 months the work will become freely available and the license terms will switch to a Creative Commons AttributionNonCommercial-Share Alike 4.0 Unported License.

Supplementary Information accompanies this paper on British Journal of Cancer website (http://www.nature.com/bjc) 